\title{
Lusioersily
}

\section{Structural and compositional changes in single wall carbon nanotube ensemble upon exposure to microwave plasma}

Roy, S., Bajpai, R., Soin, N., Sinha Roy, S., McLaughlin, JAD., \& Misra, D. S. (2017). Structural and compositional changes in single wall carbon nanotube ensemble upon exposure to microwave plasma. Journal of Applied Physics, 122(15), 154303. https://doi.org/10.1063/1.4989658

Link to publication record in Ulster University Research Portal

Published in:

Journal of Applied Physics

Publication Status:

Published (in print/issue): 18/10/2017

DOI:

10.1063/1.4989658

\section{Document Version}

Author Accepted version

\section{General rights}

Copyright for the publications made accessible via Ulster University's Research Portal is retained by the author(s) and / or other copyright owners and it is a condition of accessing these publications that users recognise and abide by the legal requirements associated with these rights.

\section{Take down policy}

The Research Portal is Ulster University's institutional repository that provides access to Ulster's research outputs. Every effort has been made to ensure that content in the Research Portal does not infringe any person's rights, or applicable UK laws. If you discover content in the Research Portal that you believe breaches copyright or violates any law, please contact pure-support@ulster.ac.uk. 
Structural and compositional changes in single wall carbon nanotube ensemble upon exposure to microwave plasma

Soumyendu Roy, Reeti Bajpai, Navneet Soin, Susanta Sinha Roy, James A. McLaughlin, and D. S. Misra

Citation: Journal of Applied Physics 122, 154303 (2017); doi: 10.1063/1.4989658

View online: http://dx.doi.org/10.1063/1.4989658

View Table of Contents: http://aip.scitation.org/toc/jap/122/15

Published by the American Institute of Physics

\section{Scilight}

Sharp, quick summaries illuminating the latest physics research 


\title{
Structural and compositional changes in single wall carbon nanotube ensemble upon exposure to microwave plasma
}

\author{
Soumyendu Roy, ${ }^{1, a)}$ Reeti Bajpai, ${ }^{2}$ Navneet Soin, ${ }^{3}$ Susanta Sinha Roy, ${ }^{4}$ \\ James A. McLaughlin, ${ }^{5}$ and D. S. Misra ${ }^{6, b)}$ \\ ${ }^{1}$ Advanced Technology Development Centre, Indian Institute of Technology Kharagpur, Kharagpur 721302, \\ India \\ ${ }^{2}$ Department of Chemistry and Thematic Unit of Excellence, Indian Institute of Technology Kanpur, Kanpur \\ 208016, India \\ ${ }^{3}$ Institute of Renewable Energy and Environment Technology, Institute for Materials Research and Innovation, \\ University of Bolton, Deane Road, Bolton BL3 5AB, United Kingdom \\ ${ }^{4}$ Department of Physics, School of Natural Sciences, Shiv Nadar University, Chithera, Uttar Pradesh 203207, India \\ ${ }^{5}$ Nanotechnology and Integrated Bioengineering Centre, University of Ulster at Jordanstown, \\ Newtownabbey BT37 OQB, Northern Ireland, United Kingdom \\ ${ }^{6}$ Department of Physics, Indian Institute of Technology Bombay, Mumbai 400076, India
}

(Received 11 June 2017; accepted 4 October 2017; published online 18 October 2017)

\begin{abstract}
Microwave plasma treatment of single wall carbon nanotube (SWNT) films called bucky papers (BPs) resulted in changes in the relative proportion of different chiralities of SWNTs present in the $\mathrm{BP}$ and the production of vertical microstructures on the surface of BP. The plasma was created using $\mathrm{H}_{2}$ gas mixed with $\mathrm{Ar}$ or $\mathrm{CH}_{4}$, at a temperature of $900{ }^{\circ} \mathrm{C}$ and a pressure of 70 Torr. Radial breathing mode spectra of the BPs revealed that the preferential sputtering by plasma is not with respect to the diameter or the metallic nature of SWNTs. We propose that the lengths of SWNTs influence how they interact with plasma. Longer tubes will have higher dielectric constants and hence will be polarized more strongly by the electric field of the plasma sheath. This in turn results in greater ion bombardment and sputtering. Finite element method was used to find the strengths of the induced electric fields on model SWNT surfaces. Microscopy, Raman, and X-ray photoelectron spectroscopy were used to study the effect of plasma on the crystallinity of the surviving SWNTs. Structural integrity of SWNTs was preserved after the plasma treatment. Published by AIP Publishing. https://doi.org/10.1063/1.4989658
\end{abstract}

\section{INTRODUCTION}

Low temperature plasma is a versatile tool for fabrication and modification of nano-materials, thin films, and semiconductors. ${ }^{1,2}$ Consisting of charged particles and excited neutrals, plasma provides a unique environment for chemical reactions, which is distinct from what one can achieve with ordinary solid, liquid, and gas phases. It has been used for synthesis, surface functionalization, doping, and purification of carbon nanotubes (CNTs) and to modify morphology of CNT based structures at the nano and microscales. ${ }^{3-11} \mathrm{We}$ had previously demonstrated that plasma treatment can convert the surface of a free standing single wall CNT (SWNT) film [otherwise known as bucky papers (BPs)] consisting of densely packed horizontal SWNTs into an array of vertical microstructures having shapes that resemble cones and pillars. ${ }^{12} \mathrm{BP}$ retains its flexibility after plasma modification and can be integrated with any device. Mixtures of $\mathrm{H}_{2}+\mathrm{Ar}$ and $\mathrm{H}_{2}+\mathrm{CH}_{4}$ gases were used for the treatment. This lithography free technique of making vertically aligned CNT microstructures was instrumental in improving the performance of devices like field emitters, supercapacitors, and dye sensitized solar cells that were fabricated using the BPs..$^{12,13}$

\footnotetext{
a) Author to whom correspondence should be addressed: anoyonline@gmail. com. Phone: +918942857481

${ }^{\text {b) Current address: IIa Technologies Pte Ltd., Singapore } 618300 .}$
}

Here, we discuss the effect of the plasma treatment on the chiral make-up of the SWNTs in BPs. There have been very few studies on the effect of plasma on the composition of SWNTs. ${ }^{14-16}$ The results presented here is in sharp contrast to the previously reported preferential etching of metallic SWNTs over the semiconducting ones. No differential etching on the basis of diameter or conducting nature was observed in our experiments. However, some tubes appeared to be sputtered or etched much faster than others. The temperature of plasma is a vital difference between ours and the previous studies. We explore the possibility of a variation in length of as synthesized SWNTs being a determining factor in the differential effect of plasma. We show that there can be significant variation in the strength of the electric field at the surface of tubes with different lengths, placed inside a plasma environment. It was also noticed that the crystallinity of the nanotubes that survived the plasma treatment did not deteriorate but rather showed a moderate improvement. These effects were studied by Raman and $\mathrm{X}$-ray photo-electron spectroscopy (XPS).

\section{EXPERIMENTAL SECTION}

\section{SWNT and BP synthesis}

SWNTs were grown by catalytic chemical vapor deposition (CVD) method. $\mathrm{CH}_{4}$ diluted with $\mathrm{H}_{2}$ gas (1:5 by volume) was blown over the heated catalyst kept at a 
temperature of $960-970{ }^{\circ} \mathrm{C}$ and under atmospheric pressure. The catalyst used is a solid solution of the bimetals Co-Mo or Fe-Mo in $\mathrm{MgO}$ (Co:Mo:MgO=1:0.5:300 and $\mathrm{Fe}: \mathrm{Mo}: \mathrm{MgO}=1: 0.5: 200$ by weight) prepared by combustion synthesis technique. Most of the SWNTs were estimated to have diameters lying between 1.13 and $1.65 \mathrm{~nm} .{ }^{17}$ The experiments reported here were generally carried out using the SWNTs made from Co based catalyst. However, there was no discernable difference with the Fe catalyst grown SWNTs. After synthesis the catalyst material was separated from the tubes by dissolution in $11 \mathrm{M} \mathrm{HNO}_{3}$ solution. Purified SWNTs were dispersed and filtered through a polyvinylidene fluoride membrane under an applied pressure gradient. ${ }^{18}$ After drying the SWNT BPs are separated from the filter by dipping in N,N-dimethyl acetamide. BPs used in these experiments were robust, flexible, $\sim 1.7-1.8 \mathrm{~cm}$ in diameter, and 10-12 $\mu \mathrm{m}$ in thickness.

\section{Plasma treatment of BP}

Plasma treatment was performed inside a microwave plasma CVD chamber (2.45 GHz frequency) with magnetron operated at $\sim 400 \mathrm{~W}$ power, temperature of $\sim 900^{\circ} \mathrm{C}$, and pressure of $\sim 70$ Torr. The base pressure of the chamber was approximately $10^{-2}$ Torr, and the gas mixtures used to create the plasma were $\mathrm{H}_{2}+\mathrm{Ar}$ and $\mathrm{H}_{2}+\mathrm{CH}_{4}$ with approximately $98 \% \mathrm{H}_{2}$ by volume in both cases. The substrate temperature was measured using an IRCON make Optical Pyrometer. $\mathrm{H}_{2}$ gas on its own was found to produce minor changes under identical conditions; therefore, heavier gases had to be mixed. $\mathrm{N}_{2}$ plasma was avoided because it is known to dope CNTs. ${ }^{8}$

\section{Raman spectroscopy}

Horiba Jobin Yvon HR 800 confocal micro-Raman spectrometer equipped with an Argon ion laser of wavelength $514.5 \mathrm{~nm}(2.41 \mathrm{eV})$, ISA LabRam system equipped with a $632.8 \mathrm{~nm}(1.96 \mathrm{eV}) \mathrm{He}-\mathrm{Ne}$ laser, and an Avalon Raman Station-CT system with a $785 \mathrm{~nm}(1.58 \mathrm{eV})$ laser was used to record the Raman spectra. Typical resolutions were better than $0.5 \mathrm{~cm}^{-1}, 2 \mathrm{~cm}^{-1}$, and $4 \mathrm{~cm}^{-1}$, respectively. The signals were recorded in back scattering geometry, at room temperature with laser powers below $5 \mathrm{~mW}$. The three different laser energies used cover almost the entire diameter range of SWNTs up to $3 \mathrm{~nm}$. The low frequency radial breathing mode (RBM) spectra of the SWNTs were analyzed in order to identify their diameters and chiralities. A detailed description of the process can be found in our previous publication $^{17}$ and it is similar to what has been reported by others. ${ }^{19-23}$ Briefly, the spectra were fitted with Lorentzian peaks having full width at half maxima (FWHM) of $16 \mathrm{~cm}^{-1} \cdot{ }^{20,21}$ Spectra obtained at 6-9 different spots were normalized, and an average of these was used for fitting. From the RBM peak frequencies $\left(\omega\right.$ in $\left.\mathrm{cm}^{-1}\right)$, the diameters ( $d$ in $\mathrm{nm}$ ) of the SWNTs were calculated using the relation $\omega=234 / d+10 .^{21,22}$ Exploiting the resonant nature of the Raman scattering from SWNTs further information regarding its atomic structure can be obtained from the RBMs. By comparing the values of laser energy and diameters of the corresponding resonant SWNTs with the coordinates of a Kataura plot, the most probable chiralities $(n, m)$ of the tubes can be estimated. The Kataura plot was calculated using tight binding approximation for nearest neighbor interactions with carbon-carbon interaction energy of $2.9 \mathrm{eV} .{ }^{19,21,24}$ Full details have been reported elsewhere. ${ }^{17}$ Tubes with $(n-m)$ equal to an integral multiple of 3 were considered metallic.

\section{Other characterizations}

The microscopic observations of the SWNTs were carried out in a high resolution transmission electron microscope (TEM, model: JEOL, JEM 2100F). The BPs after exposure to plasma were dispersed in isopropanol by ultrasonication for TEM. Surface topography of the BPs was investigated using a scanning electron microscope (SEM, model: Jeol, JSM6400). X-ray photoelectron spectroscopy (XPS) measurements used in this study were conducted in Thermo VG Scientific Multilab 2000 system with electron energy analyzer model CLAM4. The resolution of the instrument was $\sim 0.75 \mathrm{eV}$. The Al- $\mathrm{K} \alpha$ radiation ( $\mathrm{h} \nu$ $=1486.6 \mathrm{eV}$ ) lines were used for measurements, and the pressure was $4 \times 10^{-10}$ Torr.

\section{Electric field simulation}

The static electric field at the surface of the CNTs was visualized by using finite element analysis. Comsol Multiphysics version 3.3 was used for solving the Laplace's equation in the presence of dielectric media: $-\nabla \cdot\left(\varepsilon_{0} \nabla V-\vec{P}\right)=0$, where $\varepsilon_{0}$ is the permittivity of free space, $V$ is the electric potential, and $\vec{P}$ is the polarization vector. The purpose of the simulation was to get an approximate idea of how the electric field at the CNT surface changes as its length and dielectric constant change. Hence, the model used was kept very simple. It consisted of a cube of edge $20 \mu \mathrm{m}$ and a nanotube of diameter $5 \mathrm{~nm}$ placed at its center (Fig. $\mathrm{S} 3$ of the supplementary material). The length of the nanotube was set at 5,1 , and $0.1 \mu \mathrm{m}$ for the different simulations. Lower tube diameter or higher aspect ratios could not be achieved because of the constraints in computing resources. The simulations were performed in 3D mode using the electrostatic module. $\mathrm{z}=10 \mu \mathrm{m}$ wall of the cube was set at $40 \mathrm{~V}$ potential, the wall at $\mathrm{z}=-10 \mu \mathrm{m}$ was grounded and the rest were set symmetric. These boundary settings produced a uniform field inside the cube equal to that of the plasma sheath, in the absence of any perturbation due to the nanotube. The solid nanotube subdomain had dielectric constants calculated later in the text, while the rest of the space had dielectric constant of 1 . The mesh consisted of $2.8 \times 10^{5}$ tetrahedral elements, with higher density around the nanotube. Further refinement in meshing did not produce any significant changes in the electric field distribution at the tube.

\section{Results and discussions}

Initially, the top surface of BP is wavy and slightly nonuniform (shown in Fig. S1 of the supplementary material). After plasma treatment, the surface is rendered into a collection of micropillars or cones, depending on whether the plasma was created with a mixture of $\mathrm{CH}_{4}+\mathrm{H}_{2}$ or $\mathrm{Ar}+\mathrm{H}_{2}$ gases, respectively. The surface morphology is shown in Fig. 1. 


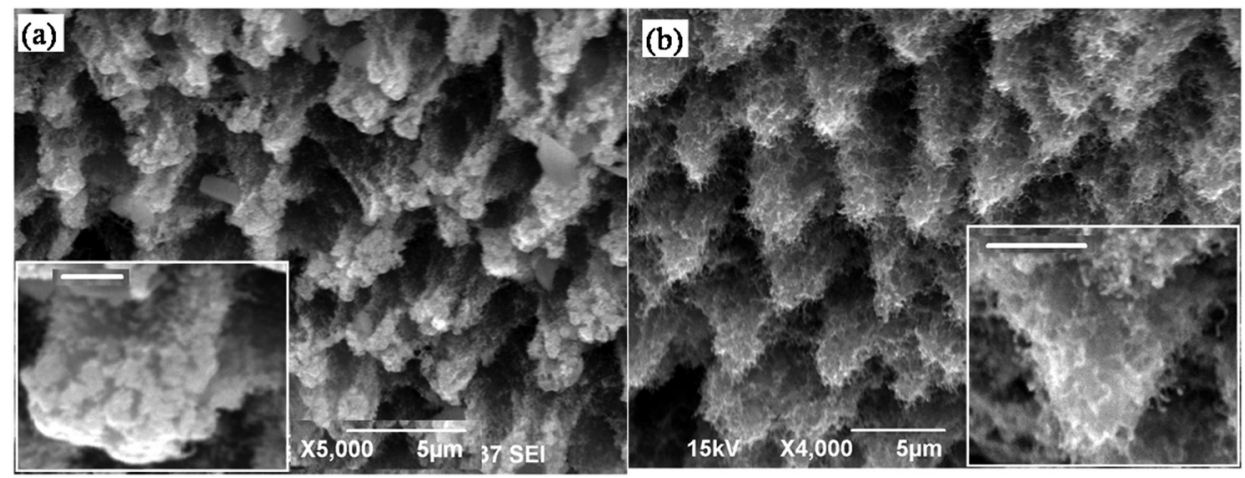

FIG. 1. Changes in the morphology of BP surface after plasma treatment. (a) Pillar type microstructures with blunt tips formed after $2 \mathrm{~h}$. of $\mathrm{Ar}+\mathrm{H}_{2}$ plasma treatment. (b) $\mathrm{CH}_{4}+\mathrm{H}_{2}$ plasma etches the top of BP more rapidly than the bottom, resulting in cone type structures with sharper tips. Scale bars of the magnified insets are (a) $1 \mu \mathrm{m}$ and (b) $2 \mu \mathrm{m}$.

A complex interplay between different factors like the plasma sheath potential, polarization of the SWNTs, inter tubular cohesive forces, and ion bombardment can result in the formation of these microstructures on the BP surface. These changes have been discussed in our previous publication. ${ }^{12}$ Spatial variations in plasma properties, both along the plane of the BP surface and perpendicular to it, may also give rise to anisotropic etching, producing microstructures of different shapes. Similar patterns produced on $\mathrm{Si}$ and other materials have been observed previously. ${ }^{25}$

Another conspicuous difference between the effects of Ar and $\mathrm{CH}_{4}$ based plasmas is the tube-like structures emanating from the cones in $\mathrm{CH}_{4}$ plasma treated BPs [see inset of Fig. 1(b)]. No such features can be seen in the pillars of Ar plasma treated BPs. These features turned out to be multiwall CNTs (MWNTs) as shown in Fig. S2 of the supplementary material. These MWNTs grew on the surface of BP during the treatment. The $\mathrm{CH}_{4}$ in the plasma provides a source of carbon, left over impurities with Fe or Co based nanoparticles enclosed inside graphitic shells provide the necessary catalytic effect, and the high temperatures $\left(\sim 900^{\circ} \mathrm{C}\right)$ of the plasma provide a suitable ambient for the growth of these MWNTs. Apart from these, the etching rates of the two types of plasmas were also different.

Raman spectroscopy revealed that although plasma treatment etches the $\mathrm{BP}$, it does not result in creation of defects in the lattice structure of SWNTs. The ratio of the intensities of the $\mathrm{D}$ band $\left(\mathrm{I}_{\mathrm{D}}\right.$, at $\sim 1350 \mathrm{~cm}^{-1}$ ) to the $\mathrm{G}$ band $\left(\mathrm{I}_{\mathrm{G}}\right.$, at $\sim 1580 \mathrm{~cm}^{-1}$ ) provides a measure of the defects in the $\mathrm{sp}^{2}$ structure of the nanotube walls. ${ }^{19,21}$ As shown in the inset of Fig. 2(a), the $\mathrm{I}_{\mathrm{D}} / \mathrm{I}_{\mathrm{G}}$ ratio drops as a result of the treatment. From an initial value of 0.1 in the pristine BP, it becomes
0.067 after $4 \mathrm{~h}$. of $\mathrm{CH}_{4}+\mathrm{H}_{2}$ plasma irradiation and 0.045 after $2 \mathrm{~h}$. of $\mathrm{Ar}+\mathrm{H}_{2}$ plasma irradiation. This is counterintuitive to what one would normally expect from an etching process. It is possible that the plasma instead of etching individual SWNTs is sputtering whole nanotubes away from the BP. Thus, the BP appears to be getting etched while the SWNTs that survive in the BP have their atomic structure undamaged. TEM imaging of the plasma treated SWNTs also confirm that the crystallinity of the nanotubes remained intact after the treatment as can be seen from Fig. 2(b).

Inset is a TEM micrograph of SWNTs obtained from the BPs treated with Ar plasma, showing the undamaged walls of individual nanotubes. The scale bar is $10 \mathrm{~nm}$.

Sputtering of whole SWNTs can explain the lack of increase in $\mathrm{I}_{\mathrm{D}} / \mathrm{I}_{\mathrm{G}}$ ratio, but cannot explain the decrease in this ratio. One possible explanation is that the plasma is knocking out the oxygen containing functional groups that were covalently bonded to the SWNT walls. These groups, mainly the hydroxyl group, are formed during the purification and BP formation step using $\mathrm{HNO}_{3}$, which is an oxidizing agent. ${ }^{26,27}$ This conjecture is corroborated by data from XPS. Figure 2(b) shows the XPS spectra before and after plasma treatment. The peak at $284.5 \mathrm{eV}$ originates from $\mathrm{sp}^{2}$ hybridized carbon atoms that make up the walls of the nanotubes. The hump at $286 \mathrm{eV}$ is a characteristic of the $\mathrm{C}-\mathrm{OH}$ bonds, ${ }^{26}$ and we found that it decreased in intensity after both Ar and $\mathrm{CH}_{4}$ plasma treatments. The carbon-oxygen weight ratio in pristine BP obtained from the ratio of the areas under the $\mathrm{C} 1 \mathrm{~s}$ and O1s peaks in the XPS spectrum is about $75 \%: 25 \%$. The exposure to $\mathrm{Ar}+\mathrm{H}_{2}$ plasma for $2 \mathrm{~h}$ and $\mathrm{CH}_{4}+\mathrm{H}_{2}$ plasma for $4 \mathrm{~h}$ reduces the oxygen content to approximately $19 \%$ and $16 \%$, respectively. It is also interesting to note that

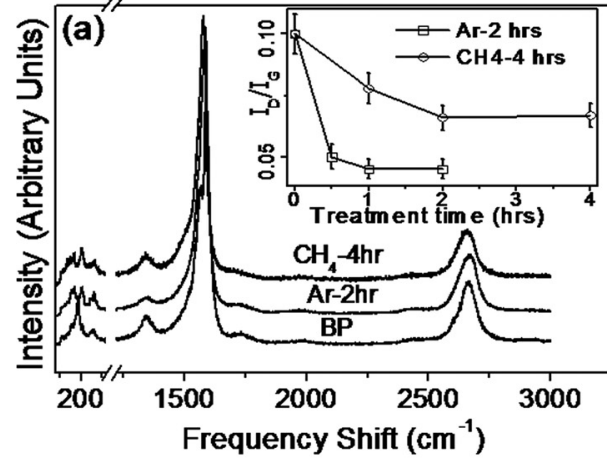

Frequency Shift $\left(\mathrm{cm}^{-1}\right)$

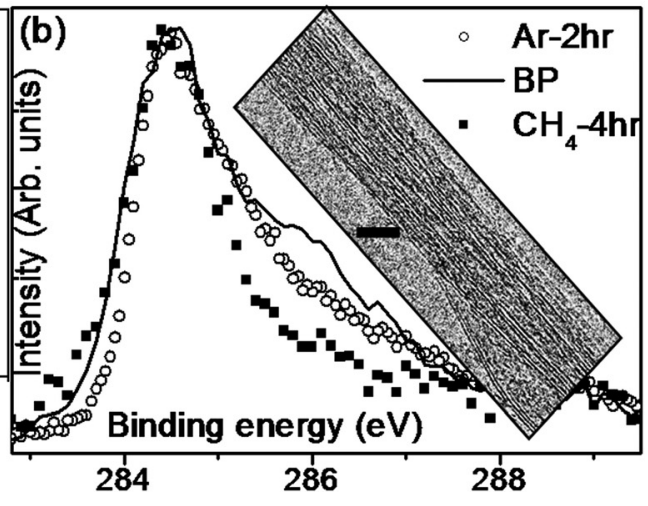

284
FIG. 2. (a) Raman spectra of original and plasma treated BPs obtained using $514.5 \mathrm{~nm}$ laser. The spectra have been normalized w.r.t. the $\mathrm{G}$ bands. Inset shows the reduction in $\mathrm{I}_{\mathrm{D}} / \mathrm{I}_{\mathrm{G}}$ ratios after exposure to plasma. (b) XPS spectra of BP before and after the plasma treatments. 

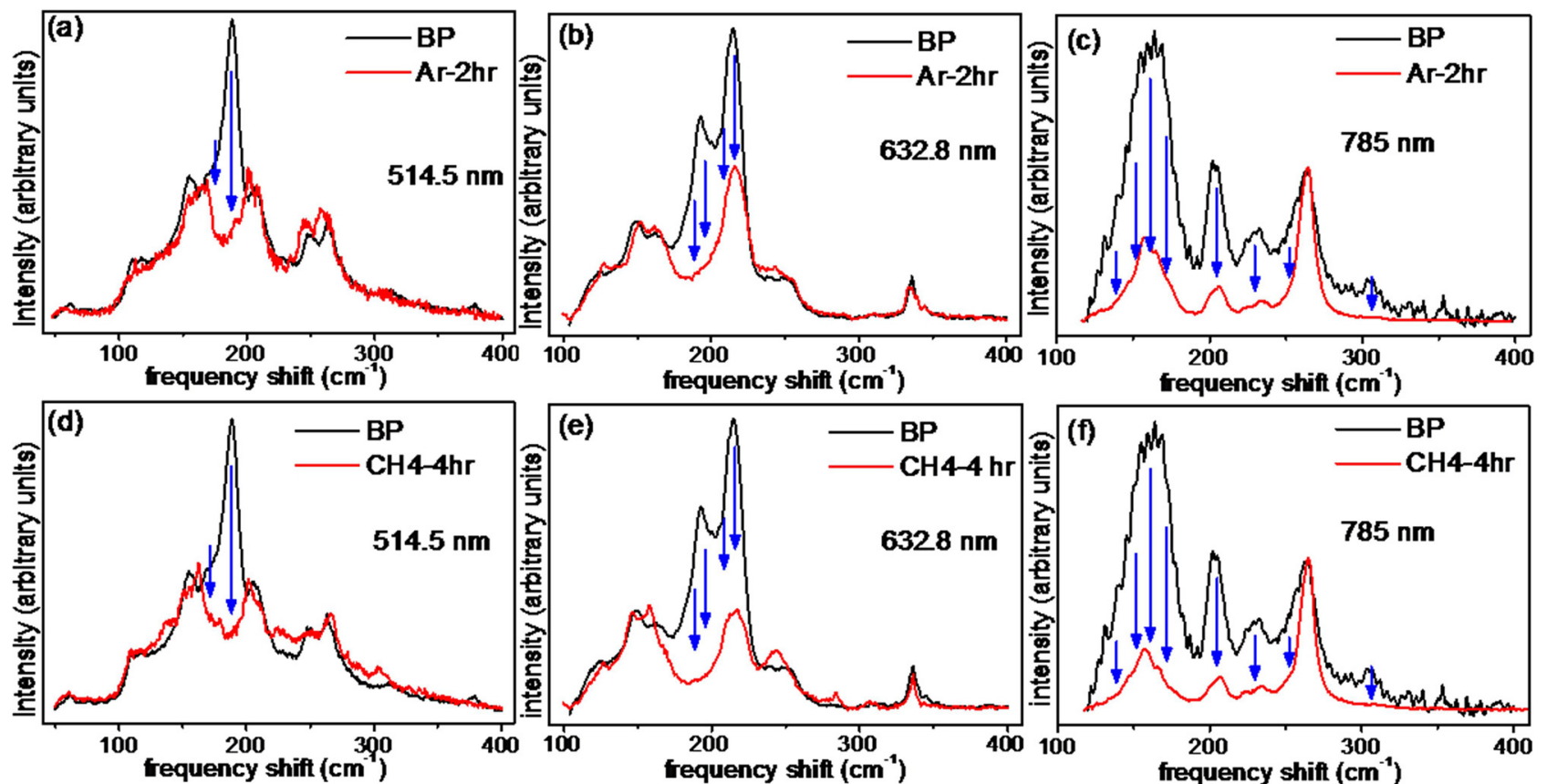

FIG. 3. The low frequency Raman spectra of BP before (black line) and after (red line) $2 \mathrm{~h}$ of Ar plasma exposure [(a)-(c)] and $4 \mathrm{~h}$ of $\mathrm{CH}_{4}$ plasma exposure [(d)-(f)]. Spectra show the selective reduction in the intensity of some of the RBM peaks. The arrows indicate the position of the peaks whose intensity is getting diminished as a result of the plasma treatment. The spectra were acquired using lasers of frequency 514.5 (left panels), 632.8 (middle panels), and $785 \mathrm{~nm}$ (right panels). The spectra were normalized such that the peaks that were least affected by the treatment had similar intensities so that they could be used as reference for comparing the before and after spectra.

although the oxygen removal is higher in the case of $\mathrm{CH}_{4}$ plasma etching, the decrease in $\mathrm{I}_{\mathrm{D}} / \mathrm{I}_{\mathrm{G}}$ ratio is much smaller. A possible reason behind this is the formation of the defective MWNTs on the surface of BP after $\mathrm{CH}_{4}$ plasma etching. Since the MWNTs cover the surface, a significant fraction of the Raman signal probably comes from them. XPS spectra also show the absence of any doping or functionalization of the nanotubes due to the treatment. It is also possible that annealing at high temperatures results in atomic rearrangements and defect healing in the SWNTs ${ }^{28}$ causing a reduction in the $\mathrm{I}_{\mathrm{D}} / \mathrm{I}_{\mathrm{G}}$ ratio.

It was observed that microwave plasma has different rates of sputtering for nanotubes with different chiralities resulting in changes in the composition of $\mathrm{BP}$ after the treatment. As shown in Fig. 3, certain RBM peaks disappear from the Raman spectrum while some others survive. From the graphs, it is also clear that the results of both $\mathrm{CH}_{4}+\mathrm{H}_{2}$ and $\mathrm{Ar}+\mathrm{H}_{2}$ plasma irradiation for 4 and $2 \mathrm{~h}$, respectively, are almost identical. The use of three different lasers for Raman spectroscopy allows a more complete identification of the different tubes present in the sample. The RBM spectra were fitted with individual Lorentzian peaks and the diameters compared with a theoretical Kataura plot to identify the chiralities. The method has been described in details in our previous publication. ${ }^{17}$ By comparing the RBM spectra before and after plasma treatment, the tubes that were getting preferentially sputtered were identified and listed in Table I.

The progressive changes in the RBMs after different plasma irradiation durations are shown in Fig. 4. The changes in the RBMs occur very quickly. It can be seen in the figure that after just $30 \mathrm{~min}$ and $1 \mathrm{~h}$ of treatment with $\mathrm{Ar}$ and $\mathrm{CH}_{4}$ based plasmas, the $188 \mathrm{~cm}^{-1}$ peak in the $\mathrm{RBM}$ spectra obtained with $514.5 \mathrm{~nm}$ laser has diminished significantly. Longer plasma treatment durations, $3 \mathrm{~h}$ with Ar and $5 \mathrm{~h}$ with $\mathrm{CH}_{4}$ mixtures, were also tested. But these only lead to more sputtering and weakening of the BP without any changes in the relative abundances of the different SWNTs.

A striking feature of the selective etching effect is that the selectivity is neither w.r.t. diameter nor the conducting nature of the tubes. Both small and large diameter tubes get etched. There does not seem to be any continuous variation with diameter. For example, in the $514.5 \mathrm{~nm}$ spectra [Figs. 3(a) and 3(d)], we can see that the two RBM peaks at 170 and $188 \mathrm{~cm}^{-1}$ (corresponding to 1.46 and $1.31 \mathrm{~nm}$ diameters) shrink as a result of the treatment, but the peaks just outside this range at approximately 155 and $210 \mathrm{~cm}^{-1}(1.61$ and $1.17 \mathrm{~nm}$ diameters) suffer relatively much less damage. Similarly both metallic and semiconducting tubes are removed by the plasma as is evident from Table I. In $514.5 \mathrm{~nm}$ spectra, both the disappearing tubes are semiconducting ones while in the $632.8 \mathrm{~nm}$ spectra only metallic tubes are removed. The $785 \mathrm{~nm}$ spectra indicate that a combination of both metallic and semiconducting SWNTs is getting sputtered.

Dai et al. ${ }^{14}$ found that exposing SWNTs to $\mathrm{CH}_{4}$ plasma etched only the metallic tubes by a hydrocarbonation reaction leaving the semiconducting ones intact. However, their study was conducted at low temperatures $\left(\sim 400^{\circ} \mathrm{C}\right)$ and with highly diffused plasma. In another study, it was found that $\mathrm{H}_{2}$ plasma could selectively etch or damage metallic SWNTs. ${ }^{15}$ Here too the authors avoided heating by exposing the samples to plasma for multiple short durations of $60 \mathrm{~s}$ each and they have used a radio frequency source. Heating 
TABLE I. Diameters and chiralities of the nanotubes that are etched most rapidly during the plasma treatment $(*=$ metallic SWNT). A few extremely low intensity peaks in the original sample have not been considered here.

\begin{tabular}{lccc}
\hline \hline $\begin{array}{l}\text { Laser wavelength } \\
(\mathrm{nm})\end{array}$ & $\begin{array}{c}\text { RBM peak } \\
\text { position }\left(\mathrm{cm}^{-1}\right)\end{array}$ & $\begin{array}{c}\text { Diameter } \\
(\mathrm{nm})\end{array}$ & $\begin{array}{c}\text { Matching } \\
\text { chiralities }(\mathrm{n}, \mathrm{m})\end{array}$ \\
\hline 514.5 & 170.39 & 1.46 & 13,8 \\
& 188.00 & 1.31 & $12,7 \quad 10,9, \quad 14,4$ \\
632.8 & 188.49 & 1.31 & $16,1^{*} \quad 11,8^{*}$ \\
& 195.71 & 1.26 & $12,6^{*}$ \\
& 209.41 & 1.17 & $10,7^{*}$ \\
785 & 217.84 & 1.13 & $11,5^{*}$ \\
& 138.70 & 1.82 & $20,5^{*} 18,8 \quad 16,10^{*}$ \\
& 151.80 & 1.65 & $12,12^{*}$ \\
& 161.00 & 1.55 & $19,1^{*}$ \\
& 170.80 & 1.46 & $16,4^{*} \quad 12,9^{*}$ \\
& 204.71 & 1.21 & 12,5 \\
& 229.78 & 1.06 & 11,4 \\
& 252.28 & 0.97 & $8,6 \quad 9,5$ \\
& 308.58 & 0.78 & 8,3 \\
\hline \hline
\end{tabular}

through simple microwave irradiation in an oven ${ }^{29-31}$ or photolysis in air by irradiation with laser of appropriate wavelength $^{32}$ is also known to destroy metallic SWNTs preferentially. As mentioned before, no such differential etching on the basis of radius and conducting nature was observed in our case. The mechanism behind preferential etching is the differential bombardment of the tubes by ions present within the plasma. Apart from the metallic nature and diameter, other parameters like length can also give rise to selective sputtering of the tubes as explained below.

The plasma will create a positively charged region called the sheath, around the BP surface. This is due to the different thermal energies of the ions and electrons in the plasma. The spatial extent of the sheath is of the order of the Debye length $(\lambda)$, which for a particular species in the plasma is given by $\lambda^{2}=\frac{\epsilon_{0} k T}{n q^{2}}$, where $\epsilon_{0}$ is the permittivity of free space, $k$ is the Boltzmann constant, $n, q$, and $T$ are the density, charge, and temperature (in Kelvin) of the particular species under consideration. ${ }^{33}$ The Debye length (in meters) for electrons turn out to be $\lambda=7.4 \times 10^{3} \sqrt{\frac{T_{e V}}{n}}$, where $T_{e V}$ is temperature of the electrons in $\mathrm{eV}$. The self-potential of plasma or sheath potential is defined as $\phi=T_{e V} \ln \left(\sqrt{m_{i} / 4 \pi m_{e}}\right)$, where $m_{i}$ and $m_{e}$ are the rest masses of the ions and electrons, respectively. In earlier studies, characteristics of the plasma formed under similar conditions with a mixture of $\mathrm{H}_{2}$ and $\mathrm{CH}_{4}$ gases in our microwave plasma CVD system have been investigated. ${ }^{34}$ The temperature and density of electrons were found to be $T_{e V} \approx 10 \mathrm{eV}$ and $n \approx 10^{12} \mathrm{~cm}^{-3}=10^{18} \mathrm{~m}^{-3}$. With these parameters, the Debye length turns out to be $20 \mu \mathrm{m}$. If we assume that similar plasma conditions prevail with $\mathrm{Ar}+\mathrm{H}_{2}$ mixture as well, then the sheath potentials due to the $\mathrm{CH}_{4}$ and $\mathrm{Ar}$ ions turn out to be $\sim 39$ and $43 \mathrm{~V}$, respectively. Potential due to $\mathrm{H}_{2}$ ions, which are more abundant, will be $\sim 28 \mathrm{~V}$. The value of the static electric field across the sheath is approximately between 1.4 and $2 \mathrm{~V} / \mu \mathrm{m}$, depending on the relative concentration of the $\mathrm{CH}_{4}$ (or Ar) and $\mathrm{H}$ ions in the sheath. This field will exist in a direction perpendicular to the BP surface.

The SWNTs will get polarized when placed in the external electric field $(E)$ and behave as dipoles. ${ }^{35-38}$ The components of the induced dipole moment $(p)$ of the nanotube along and perpendicular to its length are given by $p_{\|}=l a_{\|} E_{\|}$ and $p_{\perp}=l a_{\perp} E_{\perp}$, where $a$ is the polarizability per unit length (l). However, $a_{\perp}$ is orders of magnitude smaller ${ }^{38}$ and can be neglected here. Tight binding theory predicts an infinite $a_{\|}$ for metallic SWNTs. But using classical electrostatics and approximating the tube as a very small, solid metallic cylinder placed in an uniform external field gives $a_{\|}=\frac{l^{2}}{24(\ln (l / R)-1)}\left[1+\frac{4 / 3-\ln 2}{(\ln (l / R)-1)}\right]$, where $\mathrm{R}$ is the radius of the tube. ${ }^{37-39}$ The value of $a_{\|}$for semiconducting nanotubes obtained using tight binding approximation is much lower at $a_{\|}=17.8 \frac{R^{3}}{a_{c c}^{2} \gamma_{0}^{2}}$, where $a_{c c}$ is the carbon-carbon bond length $(0.142 \mathrm{~nm})$ and $\gamma_{0}$ is the tight binding nearest neighbor interaction energy $(2.9 \mathrm{eV}) .^{36,37}$ However, the temperature of the plasma $\left(\sim 900^{\circ} \mathrm{C}\right)$ is high enough to excite a significant number of electrons from the valence band of semiconducting tubes (whose band gap is low, $\sim 0.6 \mathrm{eV}$ for tubes of diameter $1.3 \mathrm{~nm}$ ) to the conduction band. Thus, the difference between semiconducting and metallic tubes becomes blurred ${ }^{36}$ and the metallic cylinder approximation can be used for both types of tubes.

The ions are accelerated through the sheath potential to the BP surface which is at negative potential w.r.t. plasma. Locally on the BP surface, there will be different types of tubes which will be polarized to different extents and create different local fields around themselves. Some will attract more ions as compared to others. Since the perpendicular component of polarizability is much lower than the parallel
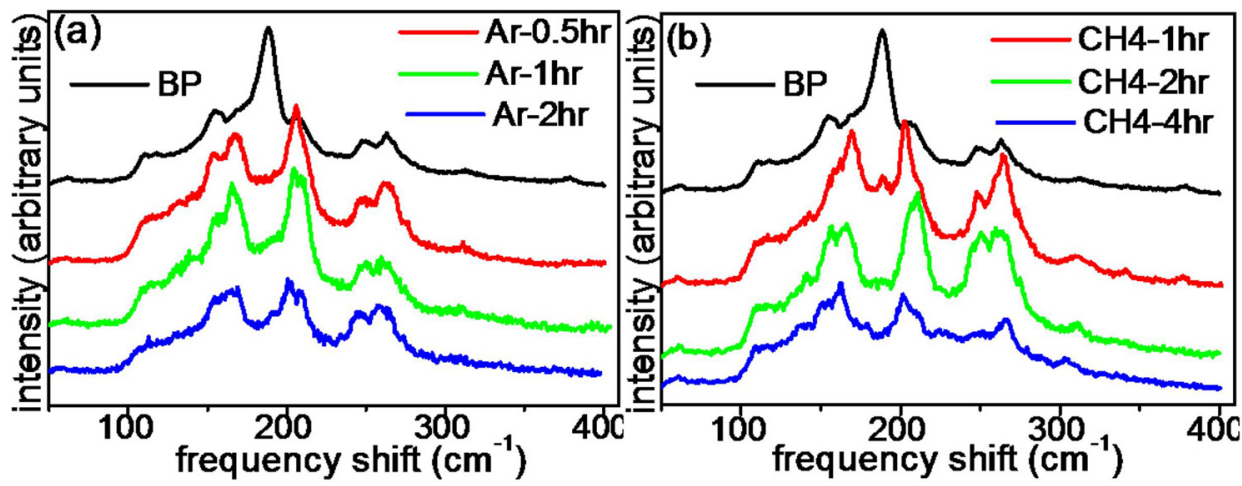

FIG. 4. The variation in the RBM spectrum of BP after different durations of (a) $\mathrm{Ar}$ and (b) $\mathrm{CH}_{4}$ plasma treatments. These spectra were recorded using $514.5 \mathrm{~nm}$ laser. 


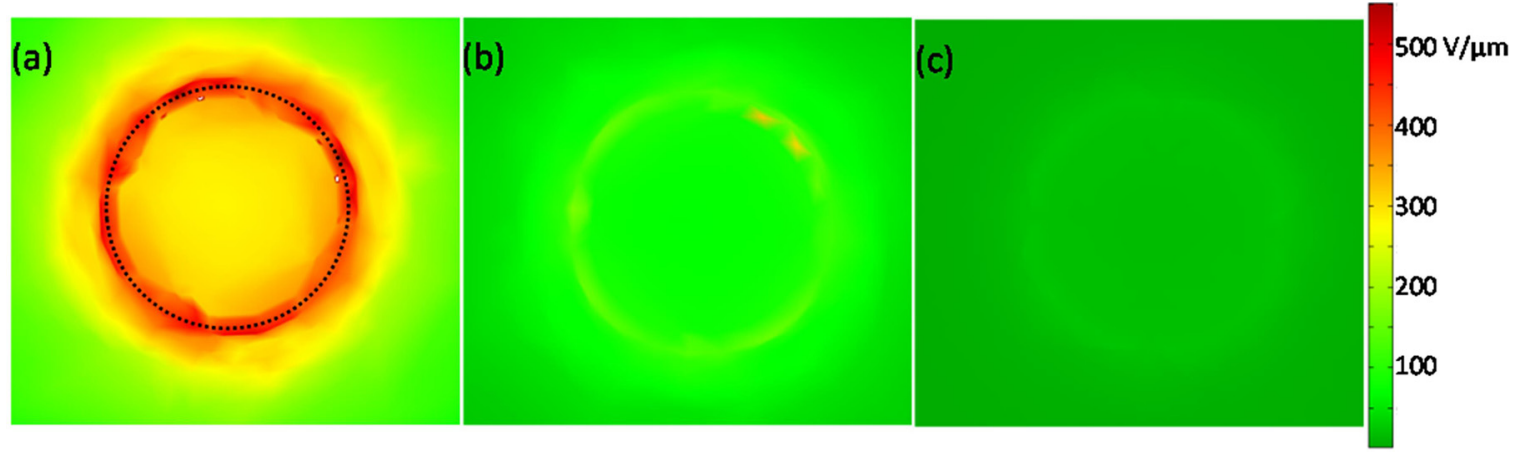

FIG. 5. Spatial distribution of electric fields at the surface of nanotubes placed in an external field of $2 \mathrm{~V} / \mu \mathrm{m}$, obtained using finite element method. The tubes have the same diameter, but different lengths (a) $5 \mu \mathrm{m}$, (b) $1 \mu \mathrm{m}$, and (c) $100 \mathrm{~nm}$. The strength of the field has been color coded. The dotted circle in (a) represents the cross-section of the nanotube.

component we can drop the subscript $\|$ for simplicity and assume the parallel components to be equal to the net values. Polarization or dipole moment per unit volume $P=a E /$ $A=\epsilon_{0} \chi E$, where $A$ is the area of cross-section of the nanotube, $\epsilon_{0}$ is the permittivity of free space and $\chi$ is the susceptibility of the tube. Hence, the dielectric constant $\epsilon_{r}=1+\chi=1+\frac{a}{A \epsilon_{0}}{ }^{40} a$ is generally expressed in units of (length), ${ }^{2}$ for converting to SI units one has to multiply it by $4 \pi \epsilon_{0}$. Hence, the dielectric constant in SI units is $1+\frac{4 a}{R^{2}}$ and it depends both on $l$ and $R$. For example, SWNTs with diameter of $1.35 \mathrm{~nm}$ and lengths $0.1,1$, and $5 \mu \mathrm{m}$ have $\epsilon_{r}$ values of about $0.1 \times 10^{4}, 6.4 \times 10^{4}$, and $124.9 \times 10^{4}$, respectively. The induced electric field just outside the nanotube is dependent on the dielectric constant. There is no simple analytical relationship between the two. Hence, the fields were simulated using finite element method.

Figure 5 shows the strength of the fields at the tips of SWNTs modeled as solid cylinders with the same diameter but different lengths, placed inside an external electrostatic field. The magnitude of the field at the edge of $5 \mu \mathrm{m}$ tube is $\sim 550 \mathrm{~V} / \mu \mathrm{m}$ while the same at $100 \mathrm{~nm}$ tube is $\sim 25 \mathrm{~V} / \mu \mathrm{m}$. Hence, ions will be preferentially attracted towards the longer tubes, causing more bombardment and sputtering. The increase in electric field strength at the SWNTs is expected from the increase in dielectric constant values. The simulation done in the current study was only meant to be an aid for visualizing this increase and not for reproducing the exact field distribution at the BP film (which consists of a random distribution of different types and spatial orientations of SWNTs) placed inside microwave plasma. Other phenomena like the complex electromagnetic interactions between the different charged species in plasma and the SWNTs or the microwave radiation and SWNTs will also affect the field distributions. Electrostatic screening effects due to adjacent tubes might further enhance the differential ion bombardment on the tubes. To account for all such processes, one would require more rigorous finite element simulation, which is beyond the scope of the current study.

It is important to note that the bombardment by ions accelerated through the plasma sheath plays a much more important role in sputtering of SWNTs than the bombardment due to the random motion of electrons. The energy of the ions due to their random thermal motion is of the order of $5-10 \mathrm{eV} .^{34,41}$ They gain an additional $28-40 \mathrm{eV}$ as they accelerate through the sheath. Electrons have an average thermal energy of $10 \mathrm{eV}$. Only a fraction of the electrons that are highly energetic will be able to cross the potential barrier of the sheath and reach the tubes. On top of that their component of motion along the field will be slowed down by the sheath potential. Length dependent ion bombardment can explain why SWNTs with certain random diameters and chiralities disappear, while others survive the plasma. Longer length results in higher $\epsilon_{r}$ and higher field at the surface that ultimately leads to more ion impingement in plasma.

\section{CONCLUSION}

Irradiation of SWNT BP with microwave plasma resulted in the preferential removal of certain tubes from the BP over others. Because of the high temperature of plasma $\left(\sim 900^{\circ} \mathrm{C}\right)$ the selectivity was not w.r.t. metallic/semiconducting nature of the nanotubes. There was also no direct correlation with diameter of the tubes. We propose that the length variation of the SWNTs could be responsible for the observed preferential removal. Approximating the SWNTs as small metallic cylinders in an external electric field, we estimate the different dielectric constants for different lengths. The strength of the electrostatic field due to plasma sheath at the SWNTs was simulated using finite element method and was found to be much higher for longer tubes of same diameter. This would result in stronger ion bombardment and faster sputtering of the longer tubes from BP. $\mathrm{I}_{\mathrm{D}} / \mathrm{I}_{\mathrm{G}}$ ratios in Raman spectra and TEM images suggest that the crystallinity of SWNTs is preserved after the treatment and XPS reveals a loss of -OH functional groups attached to the nanotubes. The treatment also created micron sized vertically aligned structures on the surface of BP. The shape of these microstructures could be changed from pillar-like to cone-like by changing the gas mixture used to create the plasma from $\mathrm{Ar}+\mathrm{H}_{2}$ to $\mathrm{CH}_{4}+\mathrm{H}_{2}$.

\section{SUPPLEMENTARY MATERIAL}

See supplementary material for TEM images of MWNTs and SWNTs, SEM images, photographs of BP, and 
diagram of the model used for simulation. This material is available free of charge via the Internet.

\section{ACKNOWLEDGMENTS}

S.R. and R.B. acknowledge the financial support from DST, India, via the DST INSPIRE Faculty Award (Nos. DST/INSPIRE/04/2015/002287 and/04/2015/002318). The authors acknowledge the Centre for Research in Nanotechnology \& Science (CRNTS), Central Surface Analytical Facility (ESCA), IRCC, IIT Bombay for the measurements. S.R. thanks United Kingdom - India Education and Research Initiative (UKIERI) for funding his work at the University of Ulster at Jordanstown.

${ }^{1}$ J. Zheng, R. Yang, L. Xie, J. Qu, Y. Liu, and X. Li, Adv. Mater. 22, 1451 (2010).

${ }^{2}$ K. Ostrikov, Plasma Nanoscience: Basic Concepts and Applications of Deterministic Nanofabrication (Wiley-VCH Verlag GmbH \& Co. KGaA, Weinheim, 2008).

${ }^{3}$ A. Kumar, S. Parveen, S. Husain, J. Ali, M. Zulfequar, Harsh, and M. Husain, J. Appl. Phys. 115, 084308 (2014).

${ }^{4}$ P. K. Tyagi, A. Misra, M. K. Singh, D. S. Misra, J. Ghatak, P. V. Satyam, and F. Le Normand, Appl. Phys. Lett. 86, 253110 (2005).

${ }^{5}$ K. S. Hazra, P. Rai, D. R. Mohapatra, N. Kulshrestha, R. Bajpai, S. Roy, and D. S. Misra, ACS Nano 3, 2617 (2009).

${ }^{6}$ I. Dumitrescu, N. R. Wilson, and J. V. Macpherson, J. Phys. Chem. C 111, 12944 (2007).

${ }^{7}$ S. Huang and L. Dai, J. Phys. Chem. B 106, 3543 (2002).

${ }^{8}$ N. Soin, S. Sinha Roy, S. Roy, K. S. Hazra, D. S. Misra, T. H. Lim, C. J. Hetherington, and J. A. McLaughlin, J. Phys. Chem. C 115, 5366 (2011).

${ }^{9}$ L. Bareket, N. Waiskopf, D. Rand, G. Lubin, M. David-Pur, J. Ben-Dov, S. Roy, C. Eleftheriou, E. Sernagor, O. Cheshnovsky, U. Banin, and Y. Hanein, Nano Lett. 14, 6685 (2014).

${ }^{10}$ A. Davydova, E. Despiau-Pujo, G. Cunge, and D. B. Graves, J. Appl. Phys. 121, 133301 (2017).

${ }^{11}$ B. B. Wang, Q. J. Cheng, X. X. Zhong, Y. Q. Wang, Y. A. Chen, and K. Ostrikov, J. Appl. Phys. 111, 044317 (2012).

${ }^{12}$ S. Roy, R. Bajpai, N. Soin, P. Bajpai, K. S. Hazra, N. Kulshrestha, S. S. Roy, J. A. McLaughlin, and D. S. Misra, Small 7, 688 (2011).

${ }^{13}$ S. Roy, R. Bajpai, A. K. Jena, P. Kumar, N. kulshrestha, and D. S. Misra, Energy Environ. Sci. 5, 7001 (2012).

${ }^{14}$ G. Zhang, P. Qi, X. Wang, Y. Lu, X. Li, R. Tu, S. Bangsaruntip, D. Mann, L. Zhang, and H. Dai, Science 314, 974 (2006).
${ }^{15}$ A. Hassanien, M. Tokumoto, P. Umek, D. Vrbanič, M. Mozetič, D. Mihailović, P. Venturini, and S. Pejovnik, Nanotechnology 16, 278 (2005).

${ }^{16}$ G. Zheng, Q. Li, K. Jiang, X. Zhang, J. Chen, Z. Ren, and S. Fan, Nano Lett. 7, 1622 (2007).

${ }^{17}$ S. Roy, R. Bajpai, N. Soin, S. S. Roy, J. A. McLaughlin, and D. S. Misra, Appl. Surf. Sci. 321, 70 (2014).

${ }^{18}$ S. Roy, V. Jain, R. Bajpai, P. Ghosh, A. S. Pente, B. P. Singh, and D. S. Misra, J. Phys. Chem. C 116, 19025 (2012).

${ }^{19}$ M. S. Dresselhaus, G. Dresselhaus, R. Saito, and A. Jorio, Phys. Rep. 409, 47 (2005).

${ }^{20}$ Z. Yu and L. Brus, J. Phys. Chem. B 105, 1123 (2001).

${ }^{21}$ A. Jorio, M. Pimenta, A. Souza Filho, R. Saito, G. Dresselhaus, and M. Dresselhaus, New J. Phys. 5, 139 (2003).

${ }^{22}$ M. S. Dresselhaus, G. Dresselhaus, A. Jorio, A. G. Souza Filho, and R. Saito, Carbon 40, 2043 (2002).

${ }^{23}$ A. Jorio, R. Saito, J. H. Hafner, C. M. Lieber, M. Hunter, T. McClure, G. Dresselhaus, and M. S. Dresselhaus, Phys. Rev. Lett. 86, 1118 (2001).

${ }^{24}$ S. Reich, C. Thomsen, and J. Maultzsch, Carbon Nanotubes: Basic Concepts and Physical Properties (John Wiley and Sons, Weinheim, 2008).

${ }^{25}$ L. Sainiemi, V. Jokinen, A. Shah, M. Shpak, S. Aura, P. Suvanto, and S. Franssila, Adv. Mater. 23, 122 (2011).

${ }^{26}$ C. Hontoria-Lucas, A. J. López-Peinado, J. d. D. López-González, M. L. Rojas-Cervantes, and R. M. Martín-Aranda, Carbon 33, 1585 (1995).

${ }^{27}$ G. Xu, Q. Zhang, W. Zhou, J. Huang, and F. Wei, Appl. Phys. A 92, 531 (2008).

${ }^{28}$ A. Ramos, I. Cameán, and A. B. García, Carbon 59, 2 (2013).

${ }^{29}$ B. R. Priya and H. J. Byrne, J. Phys. Chem. C 113, 7134 (2009).

${ }^{30}$ J. W. Song, H. W. Seo, J. K. Park, J. E. Kim, D. G. Choi, and C. S. Han, Curr. Appl. Phys. 8, 725 (2008).

${ }^{31}$ L. Wang, Y. Xiong, Z. Wu, B. Duong, S. Seraphin, H. Xin, and L. Chen, Appl. Phys. A 102, 401 (2011).

${ }^{32}$ H. Huang, R. Maruyama, K. Noda, H. Kajiura, and K. Kadono, J. Phys. Chem. B 110, 7316 (2006).

${ }^{33}$ P. M. Bellan, Fundamentals of Plasma Physics (Cambridge University Press, New York, 2006).

${ }^{34}$ T. Sharda, D. S. Misra, D. K. Avasthi, and G. K. Mehta, Solid State Commun. 98, 879 (1996).

${ }^{35}$ L. X. Benedict, S. G. Louie, and M. L. Cohen, Phys. Rev. B 52, 8541 (1995).

${ }^{36}$ Y. Zhang, A. Chang, J. Cao, Q. Wang, W. Kim, Y. Li, N. Morris, E. Yenilmez, J. Kong, and H. Dai, Appl. Phys. Lett. 79, 3155 (2001).

${ }^{37}$ E. Joselevich and C. M. Lieber, Nano Lett. 2, 1137 (2002).

${ }^{38}$ B. Kozinsky and N. Marzari, Phys. Rev. Lett. 96, 166801 (2006).

${ }^{39}$ L. D. Landau and E. M. Lifshitz, Electrodynamics of Continuous Media (Pergamon Press, Oxford, 1984).

${ }^{40}$ D. J. Griffiths, Introduction to Electrodynamics (Prentice-Hall India, New Delhi, 2000).

${ }^{41}$ K. S. Hazra, N. A. Koratkar, and D. S. Misra, Carbon 49, 4760 (2011). 